\title{
Práticas de narrativas escritas em estudantes do ensino fundamental ${ }^{* * * *}$
}

\author{
Written narrative practices in elementary school students
}

\author{
Soraia Romano-Soares* \\ Aparecido José Couto Soares** \\ Maria Silvia Cárnio***
}

*Fonoaudióloga. Mestre em Educação Especial pela Universidade de São Paulo (USP). Fonoaudióloga do Programa Saúde Escolar do Serviço Social da Indústria (SESI). Endereço para correspondência:

R. Bacaetava, 66 Apto. 101 - São Paulo - SP - CEP 04705-010

(soroso@globo.com).

**Fonoaudiólogo do Departamento de Fisioterapia, Fonoaudiologia e Terapia Ocupacional da Faculdade de Medicina da Universidade de São Paulo (FMUSP).

***Fonoaudióloga. Doutora em Linguística e Semiótica Geral pela Faculdade de Filosofia, Letras e Ciências Humanas (FFLCH) da USP. Docente do Curso de Fonoaudiologia do Departamento de Fisioterapia, Fonoaudiologia e Terapia Ocupacional da FMUSP.

****Trabalho Realizado no Departamento de Fisioterapia, Fonoaudiologia e Terapia Ocupacional da FMUSP. Parte de uma Dissertação de Mestrado realizada na Faculdade de Educação da USP.

Artigo Original de Pesquisa

Artigo Submetido a Avaliação por Pares

Conflito de Interesse: não

\begin{abstract}
Background: promotion of a written narratives production program in the third grade of an Elementary School. Aim: to analyze two written narrative practice proposals in order to verify which resources are more efficient in benefitting the textual productions of third grade Elementary School students. Method: sixty students were selected from two third grade groups of a public Elementary School in São Paulo (Brazil). For the analysis, students were divided into two groups (Group A and Group B). Fourteen children's storybooks were used. In Group A, the story was orally told by the researchers in a colloquial manner, keeping the narrator role and the original structure proposed by the author. In Group B, the story was fully read. The book was projected onto a screen and read aloud so the students could follow the reading and observe the corresponding illustrations. Voice changing resources in the characters' dialogues were used. Results: in the overall comparison, statistically significant results were found for moment (initial and final assessments) and for interaction between groups. It was observed that both groups presented substantial development from initial to final assessment. Conclusion: the Written Narratives Promotion Program based on the shared reading of children's storybooks constituted a more effective strategy than telling the stories using a single reader.
\end{abstract}

Key Words: Language; Narration; Handwriting; Education.

\section{Resumo}

Tema: promoção de um programa de narrativas escritas na terceira série do ensino fundamental. Objetivo: analisar duas propostas de trabalho com práticas de narrativas escritas com a finalidade de verificar quais recursos seriam mais eficientes para beneficiar estudantes de terceira série do Ensino Fundamental na elaboração da produção de textos. Método: foram selecionados 60 escolares de duas classes da terceira série de uma escola estadual da cidade de São Paulo. Para fins de análise, os escolares foram divididos em dois grupos (Grupo A e Grupo B); foram utilizados 14 livros de histórias infantis. No Grupo A, a história era contada oralmente de modo coloquial pelos pesquisadores, mantendo-se o papel de narrador e a estrutura original do autor. No Grupo B, a história era lida na íntegra. O livro era projetado numa tela por meio de recurso de retroprojeção e lido em voz alta para que os estudantes acompanhassem a leitura e observassem as ilustrações correspondentes. Recursos de mudança de voz nos diálogos dos personagens foram utilizados. Resultados: na comparação geral, encontraram-se resultados estatisticamente significantes para o momento (inicial e final) e para interação entre grupos. Observou-se que em ambos os grupos houve um crescimento substancial entre início e final. Conclusão: o Programa de Promoção de Narrativas Escritas com base na leitura compartilhada dos livros infantis constitui-se em uma estratégia mais eficiente do que contar das histórias por meio de uma linguagem única.

Palavras-Chave: Linguagem; Narração; Escrita Manual; Educação. 


\section{Introdução}

A linguagem escrita requer instrução (formal ou não) para ser adquirida, mesmo que se considere, atualmente, que a noção da escrita já é intrínseca na criança quando do seu ingresso na escola ${ }^{1}$. Nos países ocidentais, a instituição escolar tem grande importância, pois é o lugar de excelência em que se realiza a educação, possuindo grande influência na maturação de cada pessoa ${ }^{2}$. Porém, muitos estudantes saem da quarta série do ensino fundamental sem desenvolverem habilidades de leitura mínimas condizentes com quatro anos de escolarização ${ }^{3}$.

Sabe-se que a composição de narrativas requer uma adequada coordenação de diferentes habilidades cognitivas e de comunicação, como organização de idéias, inter-relação entre fatos e personagens, dentre outras ${ }^{4}$. Assim, a união de diferentes áreas do conhecimento no processo educacional, amplia o leque de oportunidades, favorecendo o processo ensino-aprendizagem. Nesse sentido, destaca-se a Fonoaudiologia Escolar, que propõe levar conhecimentos básicos de sua área para dentro da escola favorecendo a inter-relação profissional entre fonoaudiólogo e o professor ${ }^{5}$.

A presença do fonoaudiólogo na escola está relacionada ao sentido de criar condições favoráveis para que as capacidades dos profissionais e dos estudantes possam ser exploradas ao máximo 6 . Sendo assim, conclui-se que a atuação fonoaudiológica na escola pode implementar e/ou desenvolver programas que visem despertar o interesse pela leitura. Nesse sentido, este estudo teve por objetivo analisar duas propostas de trabalho com práticas de narrativas escritas, apoiadas em livros de histórias infantis, com a finalidade de verificar quais recursos seriam mais eficientes para beneficiar estudantes de terceira série do Ensino Fundamental na elaboração da produção de textos.

\section{Método}

A pesquisa foi aprovada sob o número 504/04, pela Comissão de Ética para Análise de Projetos de Pesquisa da Diretoria Clínica do Hospital das Clínicas e da Faculdade de Medicina da Universidade de São Paulo. Todos os responsáveis pelos estudantes que participaram da pesquisa assinaram o Termo de Consentimento Livre e Esclarecido, conforme Resolução do Conselho Nacional de Saúde (196/96).
Foram selecionados 60 escolares de duas classes da terceira série de uma escola estadual localizada na zona oeste da cidade de São Paulo. Foram programados 16 encontros semanais, sendo o primeiro e o último encontro, avaliação inicial e final, respectivamente; nos demais era realizada a leitura de uma história de livro infantil por semana, e a produção escrita de uma história com o mesmo tema. Os critérios de inclusão na pesquisa foram: estar cursando a terceira série do Ensino Fundamental I; apresentar nível alfabético de escrita ${ }^{7}$; participar das avaliações inicial e final e ter, no mínimo, $50 \%$ de frequência nos encontros do Programa de Promoção de Narrativas Escritas. Para fins de análise, os escolares foram divididos em dois grupos (Grupo A e Grupo B). Para as avaliações iniciais e finais dos estudantes, foram utilizados folhas de sulfite para registro das produções escritas dos estudantes e lápis preto número 2.

Na avaliação inicial, os grupos A e B foram trabalhados separadamente. A instrução foi dada oralmente para os dois grupos de forma idêntica. Todos os estudantes realizaram as produções ao mesmo tempo e não foi estabelecido um horário para o término. A instrução dada foi a seguinte: "imaginem que vocês estão andando num deserto. De repente, vocês encontram uma bruxa. Agora, vocês vão escrever nesta folha, uma história sobre o que aconteceu. Usem a folha da forma e do lado que quiser e escrevam o necessário. Não precisam usar borracha e nem fazer linhas".

Para o programa de promoção de narrativas escritas, foram utilizados 14 livros de histórias infantis (Apêndice), transparências para projeção (reprodução dos livros selecionados, por meio de cópia por scanner dos livros e impressão em transparência para projeção em tela), retroprojetor para reproduzir as transparências dos livros infantis e folhas de sulfite para registro das produções escritas dos estudantes. Para a escolha dos livros, o primeiro critério foi apresentar histórias inéditas para as crianças. As professoras realizaram uma préseleção das histórias, com o objetivo de evitar a leitura de livros que já fossem conhecidos pelos estudantes ou já tivessem sido trabalhados naquele ano. Todos os livros selecionados apresentavam o mesmo gênero discursivo, uma narração com sequência lógico-temporal e coerência textual adequada, que pudesse ser contada ou lida sem ambiguidade para cada grupo.

Cada história foi contada durante os 
encontros semanais, com tempo inicial determinado e duração variável, de acordo com o ritmo de cada grupo e com o tamanho do livro de histórias apresentado. A sequência das histórias trabalhadas foi rigorosamente a mesma para ambos os grupos, porém o procedimento foi diferente.

No Grupo A, a história era contada oralmente de modo coloquial pelos pesquisadores, mantendo-se o papel de narrador e a estrutura original do autor. As falas dos personagens eram contadas pelo discurso indireto para facilitar a compreensão das crianças.

No Grupo B, a história era lida na íntegra. O livro era projetado numa tela por meio de recurso de retroprojeção e lido em voz alta para que os estudantes acompanhassem a leitura e observassem as ilustrações correspondentes. Recursos de mudança de voz nos diálogos dos personagens foram utilizados, realizando mudança prosódica e ênfase ao discurso direto e ao diálogo.

A cada semana, utilizava-se uma história diferente que era apresentada em ambas as classes e antes de iniciá-la, o título do livro e o nome do autor eram sempre enfatizados. Logo após o término da história era discutido com as classes o tema do livro e quais mensagens poderiam ser extraídas da história. Ao final da discussão, os estudantes eram motivados para que escrevessem uma história a partir do tema presente na história contada.

TABELA 1. Critérios de pontuação de análise das produções escritas.

\begin{tabular}{l|c|c}
\hline \multicolumn{1}{c|}{ Competência } & Classificação & Pontuação \\
\hline \multirow{3}{*}{ genérica } & adequado & 2 \\
& parcialmente adequado & 1 \\
& inadequado & 0 \\
enciclopédica & manutenção ao tema & 2 \\
& manutenção parcial ao tema & 1 \\
\multirow{2}{*}{ linguística } & não manteve & 0 \\
& adequado & 2 \\
& parcialmente adequado & 1 \\
\hline
\end{tabular}

No último encontro, realizou-se a avaliação final com os mesmos procedimentos da inicial. A produção de texto foi solicitada a partir da seguinte instrução:"imaginem que vocês estão perdidos numa floresta. De repente, vocês encontram um disco voador. Agora vocês vão escrever nesta folha, uma história sobre o que aconteceu. Usem a folha da forma e do lado que quiser e escrevam o necessário. Não precisam usar borracha e nem fazer linhas".

Antes e após a realização do Programa de Práticas de Narrativas Escritas, os escolares desenvolveram produções escritas livres. Foram adotados os critérios das Competências Comunicativas - Genérica, Enciclopédica e Linguística ${ }^{8}$, conforme se observa na Tabela 1.

Tais critérios foram baseados nas idéias de Maingueneau ${ }^{8}$ que postula as instâncias que devem ser mobilizadas para produzir e interpretar um enunciado. Para o autor existem três competências que intervêm no conhecimento do discurso, e não se manifestam de modo sequencial, mas interagem para produzir uma interpretação. O domínio das leis do discurso e dos gêneros do discurso são componentes essenciais de nossa competência comunicativa, trata-se da competência genérica, ou seja, é a capacidade de produzir enunciados no âmbito de um certo número de gêneros. É preciso para tal, ter o domínio da língua em questão, uma competência linguística e dispor de um número considerável de conhecimentos sobre o mundo, uma competência enciclopédica.

Com base nesses critérios, analisaram-se as produções textuais iniciais e finais de cada estudante. Essas produções foram analisadas qualitativa e quantitativamente, caracterizando uma pesquisa mista.

\section{Resultados}

As avaliações iniciais e finais de cada criança foram pontuadas e analisadas por meio de análise estatística e foi aplicado o teste de ANOVA ${ }^{9}$.

Os resultados obtidos estão apresentados na Figura 1 e na Tabela 2

Os resultados relativos à comparação entre a avaliação inicial e a final, bem como a relação entre os grupos e o momento da avaliação foram estatisticamente significantes. Na comparação geral, encontraram-se resultados estatisticamente significantes para o momento (inicial e final) e para interação entre grupos. Observou-se que em ambos os grupos houve um crescimento substancial entre 
início e final, entretanto, pode-se notar que o aumento da média foi maior no Grupo B (Tabela 2).

\section{Discussão}

Todas as produções finais dos estudantes, analisadas nesta pesquisa, atingiram melhora nas três competências comunicativas, produzindo narrativas coerentes e estruturas organizadas, elaboradas com riqueza de detalhes e ações. A preocupação e cuidado dos estudantes com as produções demonstraram que, ao término do Programa de Prática de Narrativas Escritas, os textos eram mais arrojados e cada um tinha menor receio de expor suas histórias.

Os dois tipos de Programa de Práticas de Narrativas Escritas trouxeram avanços nas três competências comunicativas, resultando em textos mais estruturados, coerentes e coesos. Para alguns estudantes do Grupo A, que não tiveram progressos significativos, as produções, mesmo carentes de elementos importantes para a estrutura textual, apresentaram evolução, resultando ao leitor uma melhor interpretação da mensagem. A interação entre as competências é imperativa para remediar as deficiências ou o fracasso do recurso das outras ${ }^{8}$.

O contato com o livro e a forma como o Programa foi executado no Grupo B, possibilitou aos estudantes a busca de informações, ajuste da estrutura, atenção às regras da escrita, comparação de textos, discussão e incentivo à escrita de novas produções, sem receios e medo de expor suas dificuldades. As características linguísticas mais evidenciadas no Grupo B foram o maior uso de dêiticos espaciais e temporais, a marcação de diálogos dos personagens, uso correto de parágrafos, extensão da narrativa e melhor adequação da pontuação.

Os diferentes resultados encontrados nos dois grupos remetem a uma maior reflexão sobre os benefícios de cada programa. O fato de o Grupo B apresentar um crescimento maior do que aquele apresentado pelo Grupo $\mathrm{A}$, sugere que o trabalho baseado na multiplicidade de linguagens, produziu um avanço na escrita dos estudantes.

As conquistas obtidas com as leituras dos livros infantis possibilitam ao leitor o contato com uma estrutura completa do texto e auxiliam desde a ampliação do vocabulário até o aprimoramento da expressão oral e raciocínio lógico para as interpretações de causa e efeito.
FIGURA 1. Perfil dos Grupos A e B nas Avaliações iniciais e finais.

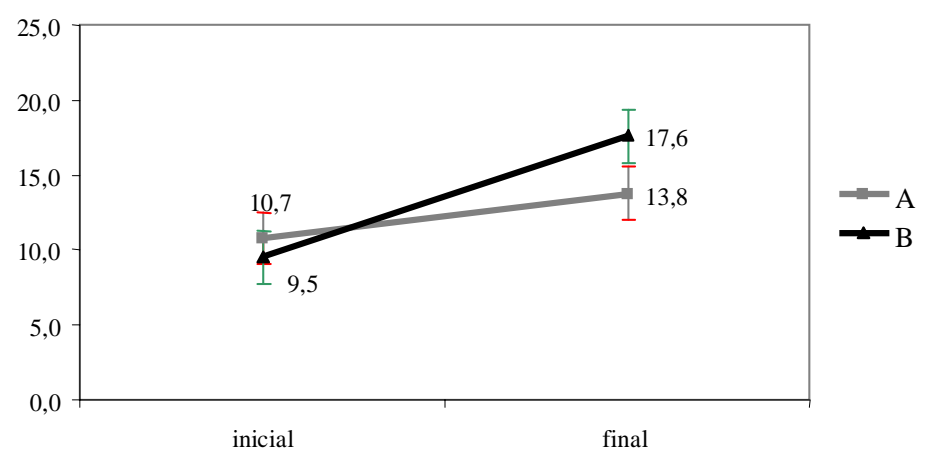

TABELA 2. Comparação entre os grupos (ANOVA).

\begin{tabular}{l|c}
\hline \multicolumn{1}{c|}{ Efeito } & p-valor \\
\hline grupos A e B & 0,2178 \\
momento (inicial e final) & $<0,0001^{*}$ \\
grupo x momento & $0,0004^{*}$ \\
\hline
\end{tabular}

O convívio com livros proporciona maior ganho e aprimoramento da linguagem escrita das crianças, principalmente se as histórias levarem a uma discussão e interpretação conjuntas entre o contador ou leitor e seus ouvintes ${ }^{10-11}$.

Resultados semelhantes foram encontrados em outra pesquisa ${ }^{12}$ após um "Programa de Empréstimo de Livros para a Família" onde foi observado ganho da consciência do uso do livro pelas crianças, além da implementação da rotina de ler em voz alta em casa. Tal hábito, promoveu o auxílio na aquisição de habilidades de leitura avançadas e de habilidades de escrita na escola.

A melhora das qualidades linguísticas após programas com estudantes corrobora os resultados de outros pesquisadores que enfatizaram maior direcionamento às tarefas de leitura e enfoque na escrita $^{13-15}$. De acordo com estes autores e complementando os achados desta pesquisa, a leitura e discussão de livros foram fundamentais para aprimorar as habilidades de escrita na escola ${ }^{16}$.

\section{Conclusão}

Os dois Programas de Promoção de Narrativas Escritas promoveram produções escritas mais elaboradas. Porém, o Programa de Promoção de 
Narrativas Escritas com base na leitura compartilhada dos livros infantis constitui-se em uma estratégia mais eficiente do que contar das histórias por meio de uma linguagem única. Este último contou com recursos prosódicos que exploraram a complexidade linguística, necessária para motivar o estudante a conceber a leitura e a produção textual como atividades prazerosas.
O trabalho fonoaudiológico inserido no contexto escolar contribui numa articulação dinâmica da Saúde com a Educação, ao enfatizar a importância da linguagem na vida das pessoas, que possibilita a construção da aprendizagem e a busca de melhor qualidade de vida, formando cidadãos críticos e capazes de se comunicar efetivamente.

\section{Apêndice}

Relação de livros utilizados no programa de promoção de narrativas escritas.

\begin{tabular}{|c|c|c|c|c|}
\hline Semana & Livro & Autor & Editora & Ano \\
\hline $1^{\mathrm{a}}$ & problemas com cachorro & Elvira Vigna & Moderna & 2003 \\
\hline $2^{\mathrm{a}}$ & a descoberta de Miguel & Marilurdes Nunes & Ática & 2002 \\
\hline $3^{a}$ & não me chame de gorducha & Bárbara Phillips & Ática & 1980 \\
\hline $4^{\mathrm{a}}$ & as maluquices do Dr. Lelé & Teresa Noronha & Poneira & 1982 \\
\hline $5^{a}$ & a risada de Biriba & Isabel Botelho & Scipione & 1989 \\
\hline $6^{a}$ & as férias da bruxa Onilda & Larreula \& Capdevila & Scipione & 1996 \\
\hline $7^{\mathrm{a}}$ & o pequeno planeta perdido & Ziraldo & Melhoramentos & 1986 \\
\hline $8^{\mathrm{a}}$ & Rita não grita & Flávia Muniz & Melhoramentos & 1995 \\
\hline $9^{a}$ & a operação do tio Onofre & Tatiana Belinky & Ática & 1994 \\
\hline $10^{\mathrm{a}}$ & franguinho Sebastião & Ricardo Soares & Moderna & 1992 \\
\hline $11^{\mathrm{a}}$ & as confusões de Aninha & Stella Carr & Moderna & 1985 \\
\hline $12^{\mathrm{a}}$ & a invasão do pensamento & Alina Perlman & Brasil & 1985 \\
\hline $13^{\mathrm{a}}$ & os porquês do coração & Conceil Corrêa da Silva/Ney Ribeiro Silva & Brasil & 1995 \\
\hline $14^{\mathrm{a}}$ & aventuras do grotão da mata & Maria Clara Machado & Brasil & 1993 \\
\hline
\end{tabular}

\section{Referências Bibliográficas}

1. Romero PG, Bolli MH, Keske-Soares M. A terapia em consciência fonológica no processo de alfabetização. PróFono Rev. Atual. Cient. 2005;17(2):175-84.

2. Küster AMB, Húngaro RO, Casteleins VL. A fonoaudiologia educacional e a escola: muito a fazer, muito a pensar, muito a estudar. Rev Diálogo Educ. 2001;2(4):12938.

3. Guidetti, AA, Martinelli SC. Compreensão em leitura e desempenho em escrita de crianças com ensino fundamental. Psic v.8 n.2 São Paulo dez; 2007.

4. Froma PR. Narrative Writing: Development and Teaching with children with writing dificulties. Top Lang Disord. 2000;20(4):15-28.

5.Temporini ED. Percepção de professores do sistema de ensino do estado de São Paulo sobre o seu preparo em saúde do escolar. Ver. Saúde Pública. 1988;22(5):411-21.

6. Zorzi JL. Possibilidades de trabalho do fonoaudiólogo no âmbito escolar e educacional. Jornal do Conselho de Fonoaudiologia. Brasília. 1999;4(2) p. 1417.
7. Ferreiro E, Teberosky A. A psicogênese da língua escrita. Porto Alegre: Artes Médicas; 1985.

8. Maingueneau D. Análise de textos de comunicação. São Paulo: Cortez; 2002.

9. Maxwell DL, Satake E. Research and Statistical Methods in Communication Disorders. Baltimore: Williams \& Wilkins; 1997.

10. Baker L, Scher D, Mackler K. Home and family influences on motivations for reading. Edu Psycholog. 1997;32(2):69-82.

11. Bus AG, Vanijzendoorn MH. Mothers Reading to Their 3-Year-Olds: The Role of Mother-Child Attachment Security in Becoming Literate. Read Res Quart. 1995;30(4):998-1015.

12. Yaden DB, Tardibuono JM. The emergent writing development of urban latino preschoolers: Developmental Perspectives and Instructional Enviroments for secondlanguage learners. Reading \& Writing Quarterlu. 2004;20(1)29-61. 
13. Vieiro P, Garcia-Madruga JA. An analysis of story comprehension through spoken and written summaries in school-age children. Read and Writing. 1997;9:41-53.

14. Hadley P. Language Sampling Protocols for Eliciting Text-Level Discourse. Lang Speech and Hear Serv Schools. 1998;29:132-47.
15. Kaderavek JN, Sulzby E. Narrative Production by Children With and Without Specific Language Impairment Oral Narratives and Emergent Readings. Jour Speech Lang and Hear Res. 2000;43:34-49.

16. Scott CM, Windsor J. General Language Performance Measures In Spoken and Written Narrative and Expository Discourse of School-Age Children with Language Learning Disabilities. J Speech Lang Hear Res. 2000;43:324-39. 